\title{
Artificial pneumothorax: tapping into a small bit of history
}

Previously published at www.cmaj.ca

A s they take a humorous look at the procedure of inducing a pneumothorax, these photographs of in-patients from a sanatorium near Gratz, Austria, in the 1930s also take us on a truncated journey through the history of medicine.

Tuberculosis is one of the oldest diseases of civilization, with its clinical manifestations eloquently described by Hippocrates and other ancient writers. ${ }^{1}$ The bacillus responsible for tuberculosis has been identified in Egyptian mummies dating to $3000 \mathrm{BC}$.

This sequence of photographs begins with the clinical lesson recalling Pierre-Joseph Desault (1738-1795), a surgeon at the Hotel-Dieu in Paris, France, who introduced bedside clinical teaching in the late 18th century. ${ }^{2}$ It then moves on to Josef Leopold Auenbrugger (1722-1809), who described percussion of the chest, René Laennec (1781-1826), who invented the stethoscope in the late 19th century, ${ }^{1}$ finally to Wilhelm Röentgen (18451923) who discovered $x$-rays in $1895 .{ }^{1.2}$ We may infer from the image of the young men wearing futuristic-looking goggles (Figure 1) just how revolutionary this new technology was at the time. These advances, along with the discovery in 1882 of the tubercle bacillus by Robert Koch (18431910), ${ }^{2,3}$ permitted a more thorough understanding of tuberculosis and paved the way for improved methods of diagnosis and treatment.

In the 18th century, French physicians noticed that patients with tuberculosis who developed spontaneous pneumothoraces improved. ${ }^{1,3}$ By the late 19th century, Carlo Forlanini (1847-1918) had developed a technique to induce pneumothorax, forcing nitrogen into the chest through a needle pleurocentesis (Figure 2), thus collapsing the lung in an attempt to close tuberculous cavities (Figure 3 ) ${ }^{1-3}$ Artificial pneumothorax was independently developed as a treatment in the United States, but did not gain widespread popularity there until several years later. ${ }^{1-3}$ Although the procedure was an important part of treatment until the introduction of effective antibiotics, tuberculosis remained such an overwhelming public health problem that it provided a powerful stimulus for continued surgical innovation. ${ }^{1,3,4}$ In this way, the treatment of tuberculosis really laid the foundations of modern thoracic surgery. ${ }^{1-4}$

\section{George Rakovich MD}

Thoracic surgeon

Department of Surgery

Hôpital Maisonneuve-Rosemont University of Montréal

Montréal, Que.

Acknowledgements: The author thanks Dusan Caricevic, a retired physician and dentist in Montréal, Quebec, for contributing these photographs. Caricevic, who at the age of 94 has a seemingly endless store of medical anecdotes, was admitted to the Gratz sanatorium with some form of pleurisy when he was around 15 years old.

This article is dedicated to the thoracic surgical staff at Laval hospital, Ste-Foy, Quebec.

\section{REFERENCES}

1. Rosenblatt MB. Pulmonary tuberculosis: evolution of modern therapy. Bull N Y Acad Med 1973;49:163-96.

Ellis H, editor. A history of surgery. London (UK): Greenwich Medical Media; 2001. p. 264

Sakula A. Carlo Forlanini, inventor of artificial pneumothorax for treatment of pulmonary tuberculosis. Thorax 1983;38:326-32

4. Bynum WF, Porter R, editors. Companion Encyclopedia of the History of Medicine. Vol.1-2. New York (NY): Routledge;1997. p. 1864

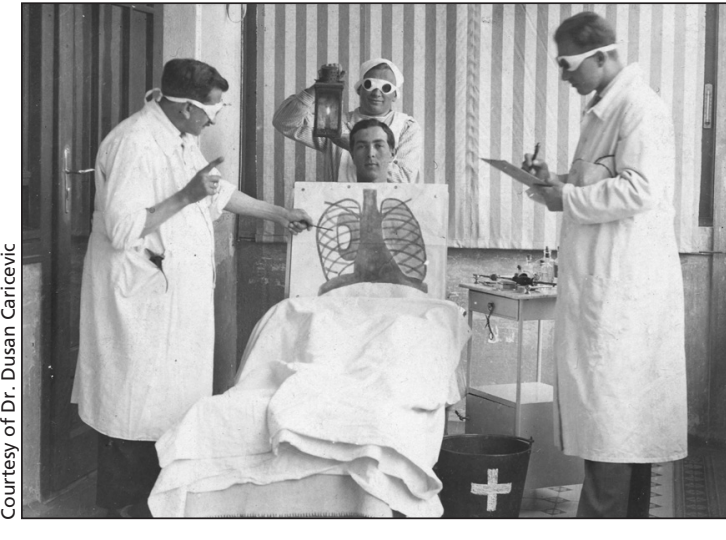

Figure 1: The clinical lesson. An old-fashioned lantern provides the source of $x$-ray radiation (circa 1930).

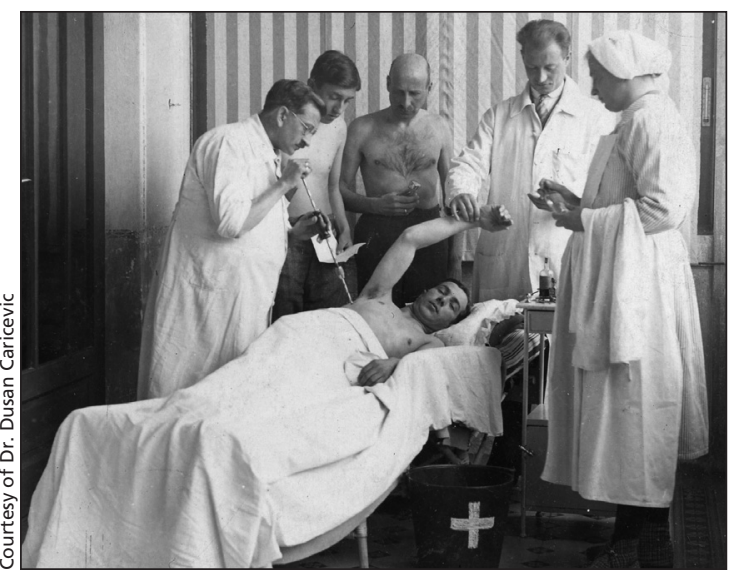

Figure 2: Pleurocentesis is performed while the patient is being monitored (circa 1930).

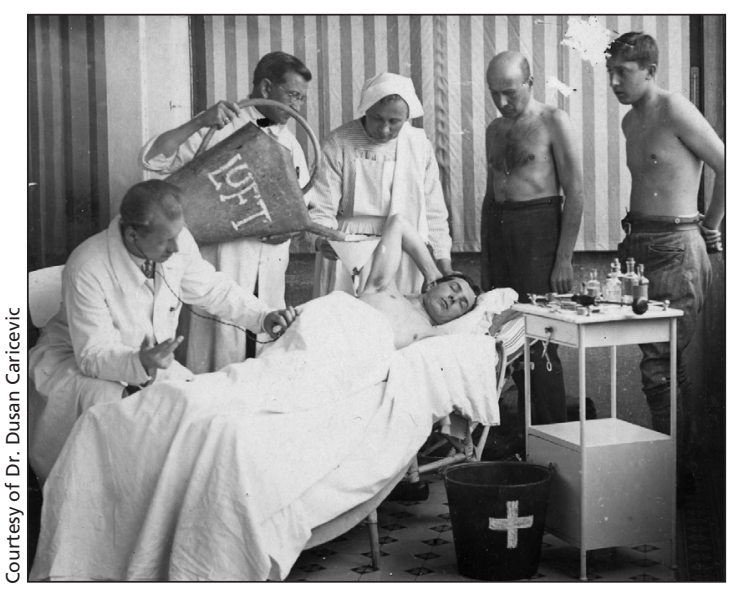

Figure 3: Creation of a pneumothorax: Ignoring physiologic principles, air (luft) is introduced into the chest (circa 1930). 